\title{
Feasibility and potential effects of using the electro-dress Mollii on spasticity and functioning in chronic stroke
}

\author{
Susanne Palmcrantz ${ }^{*}$, Gaia Valentina Pennati, Hanna Bergling and Jörgen Borg
}

\begin{abstract}
Background: Spasticity after lesions of central motor pathways may be disabling and there is a need for new, costeffective treatment methods. One novel approach is offered by the electro-dress Molliiø, primarily designed to enhance reciprocal inhibition of spastic muscles by multifocal, transcutaneous antagonist stimulation.

Methods: The Mollii ${ }^{i}$ suit was set individually for 20 participants living with spasticity and hemiplegia after stroke and used in the home setting for 6 weeks. Usability and perceived effects were monitored by weekly telephone interviews. Outcome was assessed by use of the NeuroFlexor ${ }^{\mathrm{TM}}$ method for quantification of the neural component (NC) of resistance to passive stretch (spasticity), and the modified Ashworth scale (MAS) for total resistance, FuglMeyer Assessment of motor recovery for sensorimotor function in upper (FM-UE) and lower extremities (FM-LE), activity performance with the Action Research Arm Test (ARAT), Berg balance scale, $10 \mathrm{~m}$ and $6 \mathrm{~min}$ walk tests, and perceived functioning with the Stroke Impact Scale.
\end{abstract}

Results: Compliance was high (mean 19.25 of 21 sessions). Perceived positive effects were reported by $60 \%$ and most commonly related to decreased muscle tone $(n=9)$, improved gait pattern function $(n=7)$ and voluntary movement in the upper extremity $(n=6)$. On a group level, the NC decreased significantly in the wrist flexors of the affected hand $(p=0.023)$ and significant improvements according to FM-UE $(p=0.000)$ and FM-LE $(p=0.003)$ were seen after the intervention. No significant difference was detected with MAS or assessed activity performance, except for the ARAT $(p=0.000)$. FM-UE score change correlated significantly and fairly with the perceived effect in the upper extremity $(r 0.498 p=0.025)$ and in the corresponding analysis for the FM-LE and perceived effect in the lower extremity $(r=0.469 p=0.037)$.

Conclusion: This study indicates that the Mollii ${ }^{\circledR}$ method is feasible when used in the home setting to decrease spasticity and improve sensorimotor function. The results may guide a larger controlled study combined with rehabilitation interventions to enhance effects on activity and participation domains.

Trial registration: NCT04076878. Registered 2 September 2019 - Retrospectively registered

Keywords: Stroke, Spasticity, Home setting, Self-perceived, Clinical assessments, Outcome, Self-administered

\footnotetext{
* Correspondence: susanne.palmcrantz@ki.se

Karolinska Institutet, Department of Clinical Sciences, Danderyd Hospital, Division of Rehabilitation Medicine, Entrévagen 8, SE-182 88 Stockholm, Sweden
}

(c) The Author(s). 2020 Open Access This article is licensed under a Creative Commons Attribution 4.0 International License, which permits use, sharing, adaptation, distribution and reproduction in any medium or format, as long as you give appropriate credit to the original author(s) and the source, provide a link to the Creative Commons licence, and indicate if changes were made. The images or other third party material in this article are included in the article's Creative Commons licence, unless indicated otherwise in a credit line to the material. If material is not included in the article's Creative Commons licence and your intended use is not permitted by statutory regulation or exceeds the permitted use, you will need to obtain permission directly from the copyright holder. To view a copy of this licence, visit http://creativecommons.org/licenses/by/4.0/. The Creative Commons Public Domain Dedication waiver (http://creativecommons.org/publicdomain/zero/1.0/) applies to the data made available in this article, unless otherwise stated in a credit line to the data. 


\section{Background}

Spasticity, in terms of "velocity dependent increase of resistance to passive muscle stretch" [1], is a common manifestation of "muscle overactivity" seen in spastic paresis [2] that may follow lesions of central sensorimotor pathways, such as after stroke, traumatic brain injury, in cerebral palsy or spinal cord injury and may be associated with increased impairments, activity limitations and restrict participation [3-5]. In addition to the human costs, the estimated direct costs for managing patients with spasticity after stroke are approximately four times higher than for patients without spasticity [4]. Treatment of spastic paresis is based on comprehensive physiotherapy, which may be combined with pharmacological and surgical treatments if needed. After stroke, today's first line add-on therapy is by use of intramuscular injections of botulinum toxin A (BTX). There is consistent evidence that focal spasticity and associated disabilities after stroke may be reduced by this treatment [6-12] but also that issues remain. Recently, a systematic review by Andringa et al. [9] concluded that while treatment with BTX in the upper limb improves passive movement of spastic wrist and fingers as well as selfcare, there is also a demonstrated lack of effects on armhand activity performance. A corresponding review of the literature on treatment of lower limbs by Gupta et al. [12] found that the evidence on effects on mobility was not robust and pointed out the need for new controlled trials. Although treatment with BTX is well established, it is not generally available, not all patients respond well and the maximal dose does not always allow treatment of multifocal spasticity.

Another treatment approach in this area is modulation of sensorimotor input by use of transcutaneous electrical nerve stimulation (TENS) which can be self-administered and is considered cost-effective, with few side effects and thus a promising alternative or complement to current standard therapies [13]. Recent, systematic reviews suggest that treatment with TENS transcutaneous may have beneficial effects on spasticity after stroke [13-15]. These findings, lend support to the new treatment method, the electro-dress Molliiं, evaluated in this study, which offers TENS to be applied at multiple stimulation points.

The Molliii method has been developed by Inerventions $\mathrm{AB}$, which is a Swedish medtech company, and represents an innovative approach for non-invasive electro-stimulation to reduce spasticity and improve motor function. The Mollii method is provided in a tight fitting, whole body suit with multiple electrodes that can be set individually. The Mollii method uses low frequencies and low intensities that evokes sensory input but does not elicit muscle contractions. The theoretical background of this method primarily refers to the concept of reciprocal inhibition, i.e. that sensory input from a muscle may inhibit the activation of an antagonistic muscle through activation of disynaptic reciprocal Ia inhibitory pathways $[16,17]$. Thus, the application of Mollii aims at stimulating an antagonist muscle (e.g. the anterior tibial muscle) to reduce the reflex mediated muscle over-activity in an antagonist muscle (e.g. the gastrocnemius muscle), by inducing reciprocal inhibition. However, as for conventional low intensity TENS, other mechanisms related to altered sensory input, may also play a role [13].

There is now a growing experience from pilot applications of Mollii in patients with cerebral palsy and stroke indicating that application of this method is feasible and may have beneficial effects on spasticity related disabilities [18]. However, specific effects on spasticity and how these relate to perceived and assessed functioning and disability remain to be demonstrated.

Thus, the aims of this study were to explore the feasibility of using the Mollii suit in the home setting for 6 weeks and to explore potential effects on functioning in chronic stroke. Specific aims were to explore the clinical relevance in terms of: 1) perceived usability 2) potential self-reported and assessed changes in spasticity and other functioning after the 6 weeks intervention and 3) if these potential changes were associated with level of functioning and 4) perceived changes in functioning.

\section{Methods \\ Setting}

This study was performed at the University Department of Rehabilitation Medicine, Danderyd Hospital in Stockholm, Sweden.

\section{Design and study population}

Using an explorative single group design, a convenient sample of 20 participants was planned to take part in the intervention. Eligible participants had suffered a stroke $\geq 12$ months earlier (verified by CT or MRI examination) and were living with hemiplegia affecting the right or the left side of the body including both upper and lower extremity function. They were able to walk with assistance or independently according to the Functional Ambulatory Categories [19] with a score of 2-5. Activity in upper extremity was limited according to the Action Research Arm test (ARAT) [20] but a grasp and grip movement could be voluntarily performed. Moreover, eligible study participants were $>17$ years old, able to understand instructions as well as written and oral study information and could express informed consent.

Exclusion criteria comprised no detected neural component exceeding the cut off for spasticity according to the NeuroFlexor ${ }^{\text {su }}$ ( $>3.4$ Newton) in the wrist flexors [21], contractures not compatible with performing the NeuroFlexor $^{\mathrm{Tm}}$ test, any other disorder with an impact on 
sensorimotor function, any other severe concomitant disease (such as cancer, cardiovascular, inflammatory or psychiatric disease), uncontrolled epilepsy or blood pressure, major surgery during the last year, any implanted medical devices, pregnancy and BMI $>35$.

Participants with ongoing pharmacological treatment (e.g. with Baclofen) could be included only if the medication was stable since at least 3 months and no change during the study period was anticipated. Participants, who had been subject to intramuscular treatment for spasticity could participate only if the time since last treatment was 3 months or more and if it was anticipated that next treatment would not be given during the study period.

Eligible participants were identified in out-patient care in Stockholm, Sweden, by physiotherapists who informed the patient about the study and asked the patient for consent to be contacted by the study coordinator who obtained informed consent. First enrollment was in August 15, 2017 and study completion in February 1, 2019.

\section{Intervention}

As the method is based in the theory of reciprocal inhibition of the spastic muscle [16, 17], the Mollii ${ }^{\circ}$ suit (Inerventions $A B$, Danderyd, Sweden) was set to stimulate the antagonist of the spastic muscles by a person trained in the Mollii ${ }^{\circ}$ method. These settings were based on the results of the assessment (presented in the data collection section) performed and reported by the experienced physiotherapist in the study who was not otherwise involved in the settings. During donning, the trousers are put on first as presented in Fig. 1. Next the user proceeds to put on the jacket and zip it up. The Mollii ${ }^{\circ}$ suit has a tight fit to allow the electrodes to adhere to the skin surface (Fig. 1). The control units were programmed before use and connected to the suit. Clinical experience and follow-up with users have shown that the Mollii ${ }^{\circ}$ suit have detectable effects at $20 \mathrm{~Hz}$ of stimulation when used every second day $60 \mathrm{~min} / \mathrm{session}$. Thus, in this study, the suits were set at $20 \mathrm{~Hz}$ and to stimulate for $60 \mathrm{~min} / \mathrm{session}$.

The participants were instructed in how to use the Mollii ${ }^{\oplus}$ suit and to use the suit for $60 \mathrm{~min}$, every second day, for 6 weeks (21 sessions). Study participants were encouraged to continue everyday life activities as usual.

\section{Data collection}

An experienced physiotherapist and a physician, both trained in the data collection methods performed the assessments of the participants' functioning and disability before the intervention (M1) and repeated at the end of the 6 weeks period (M2).

\section{Characteristics of participants}

Characteristics were collected in terms of age, sex, diagnosis, paretic side, time to inclusion from stroke onset and independence in walking with the Functional Ambulation Categories [19] as well as independence in self-care and mobility by use of the Barthel Index [22].
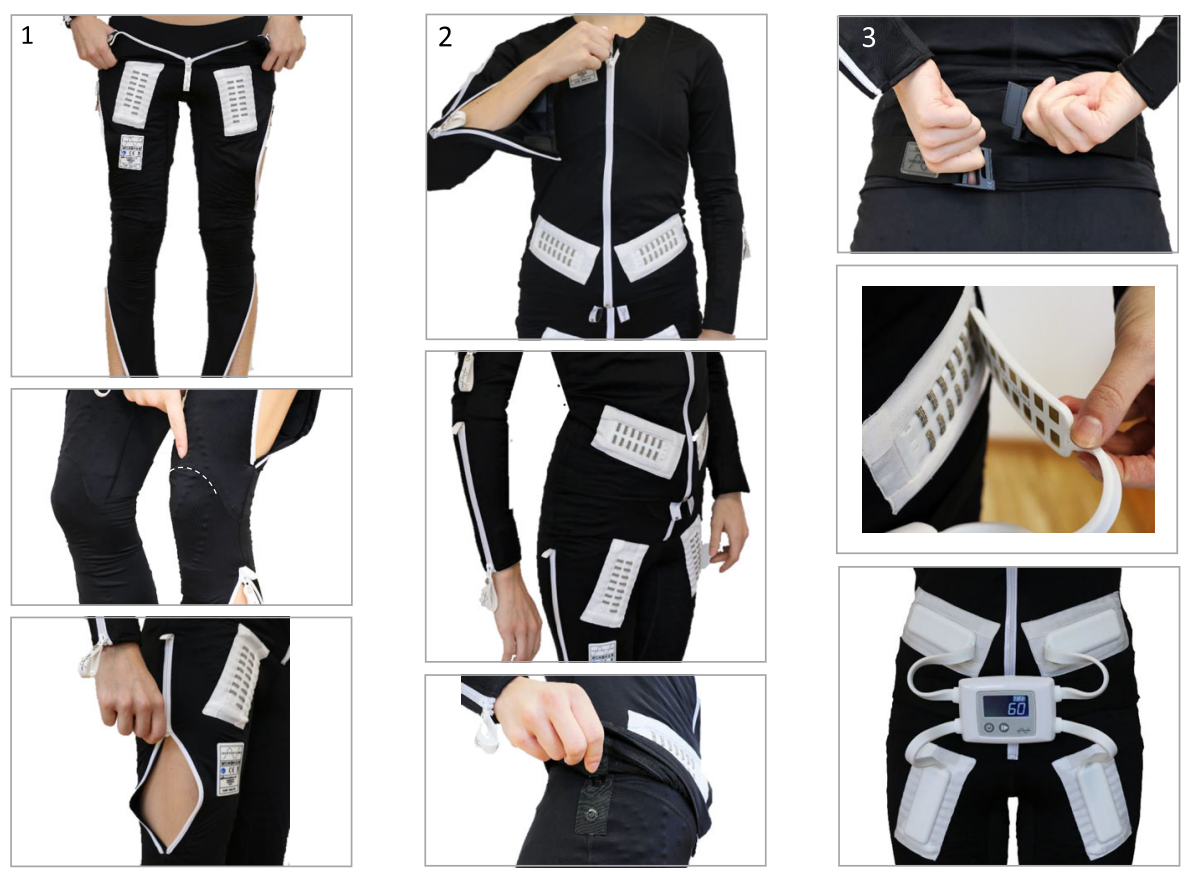

Fig. 1 Donning of the Mollii ${ }^{\circledR}$ suit - trousers [1] and jacket [2] and connection of the control unit to the suit [3] 
Cognitive function was assessed with Montreal Cognitive Assessment [23].

\section{Usability and perceived effects}

Participants perceptions of using the suit in the home setting was collected in weekly telephone interviews during the 6 weeks intervention by an experienced physiotherapist. The interview questions are presented in Fig. 2. The response to each question was recorded in a log-book by the interviewer. Perceived effects were analyzed and coded A) according to the International Classification of Functioning and Disability [24] and B) into 1) no effect, 2) potentially positive and 3) positive effect and further into C) effects in 1) upper, 2) lower extremity and 3) general effects. The coding was discussed with the data collector to assure consistency and validity. During the last telephone interview, the participants were asked to rate the overall usability of the suit on a 10-point scale ranging from 1 (no usability) to 10 (maximum usability).

\section{Assessments related to spasticity}

The neural component (NC), of resistance (Newton) to passive muscle stretch of the wrist flexors according to the NeuroFlexor $^{\mathrm{rax}}$ method (Aggero MedTech AB, Solna, Sweden) was recorded at 3 time points (A1-A3) before the intervention to assess potential fluctuations in $\mathrm{NC}$ and at
M1 and M2, to assess potential change over the intervention time. Further, NC was quantified before and during one test treatment session before the intervention started in order to explore immediate effects of the treatment. These tests were performed with the participant at rest, in a sitting position. The NeuroFlexor ${ }^{\text {Tw }}$ incorporates a neuro-biomechanical computerized model that allows quantifying and differentiating the neural reflex contribution (here defined as spasticity according to Lance [1]) and mechanical contributions to total resistance to passive muscle stretch. The validity, reliability and sensitive to change of this method have been demonstrated [25-27]. Reference data for upper limb have been published [21]. Measurements were carried out bilaterally.

The Modified Ashworth Scale (MAS) is a 6 step ordinal scale [28] and is commonly used in clinical practice and clinical research. The MAS scale does not separate mechanical and neural contributions to passive movement resistance in a spastic muscle [29]. Although the MAS has several recognized limitations, it is widely used and enables assessments of both upper and lower extremities. Thus, spasticity according to the MAS (range 0 (no spasticity) to 5 (rigidity)) was assessed at M1 and M2 in both upper- (internal rotators of the shoulder, extensors and flexors of elbow, pronators and supinators of forearm and flexors of the wrist, and fingers) and the lower extremity (hip adductors, knee

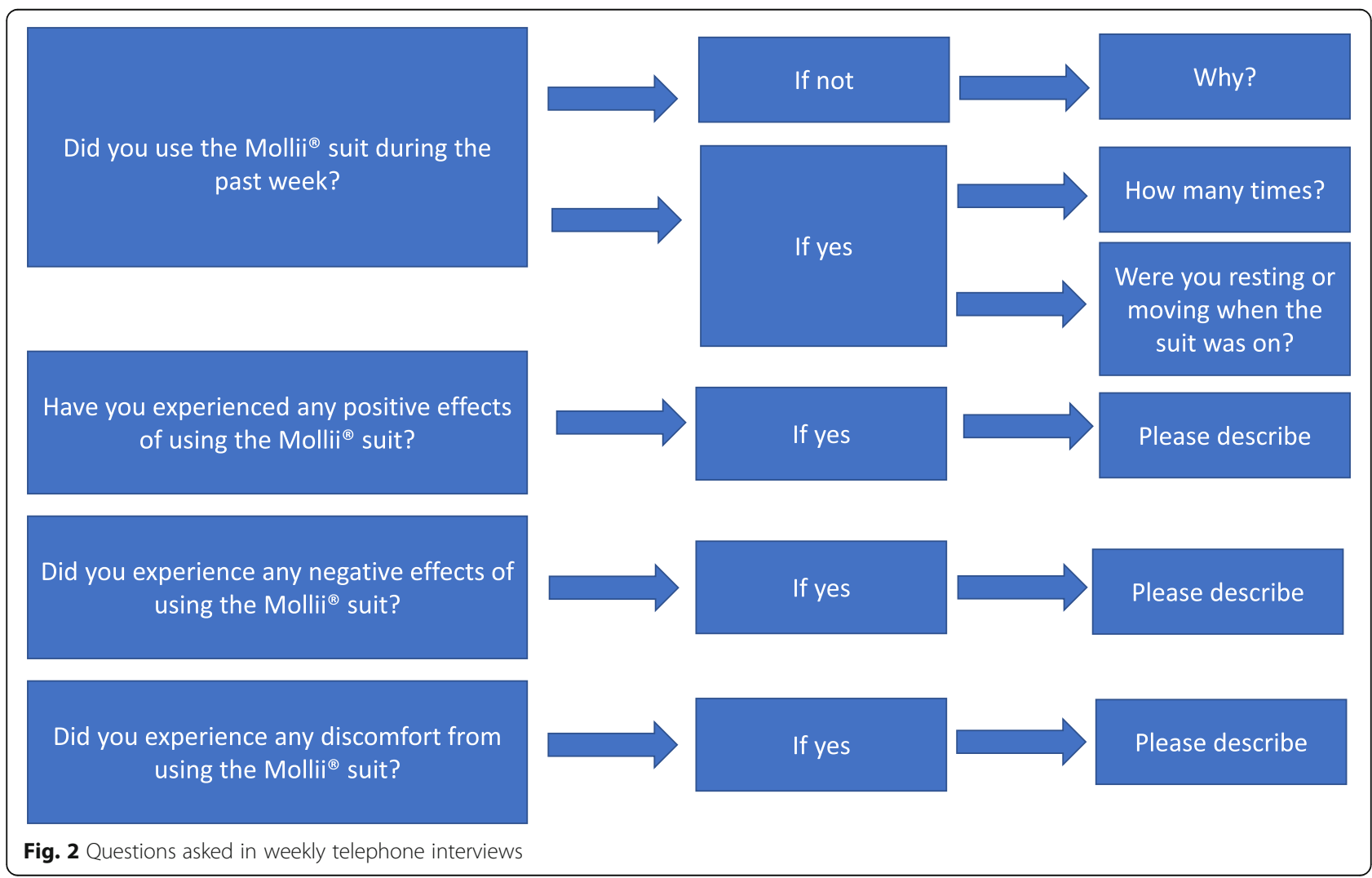


flexors and extensors, ankle plantar flexors (soleus and gastrocnemius and) and supinators of the ankle). Results are presented for the flexors of the wrist and were summarized for the upper extremity (maximum score 35p) and lower extremity (maximum score 30p). Measurements were carried out bilaterally.

\section{Additional assessments of functioning and disability performed at $M 1$ and $M 2$}

To assess sensorimotor function in the upper and lower extremity, the Fugl-Meyer Assessment of motor recovery (FM) for the upper (FM-UE) and lower (FU-LE) extremities were used (including motor-, sensory- and passive joint function and pain rated on a 3 point scale) [30]. Grip strength (kilogram) was measured by use of a digital hand dynamometer (www.Saehan.com). The Action Research Arm Test (ARAT) [20] was used as an observational rating scale of upper extremity performance including a 4 point scale assessing the performance of grasp, grip, pinch and gross movement. Walking speed was assessed with the $10 \mathrm{~m}$ walk test [31] (for walking speed in seconds). The 6 min walk test was used to test endurance (in meters) [32]. Balance was assessed by means of the Berg Balance Scale (14 items including static and dynamic movements rated on 5-point scales) [33, 34]. Finally, the participants' perception of functioning and disability was assessed with the Stroke Impact Scale (SIS) where each question is responded to using a 6-point scale and a summary score for each of the 7 domains is calculated by use of an algorithm $[35,36]$.

\section{Statistics}

Descriptive statistics was presented as mean and standard deviation (SD) for normally distributed continuous data and as median and interquartile range (IQR) for ordinal and not normally distributed data (detected with the Shapiro-Wilk test). To assess differences between more than two timepoints, Related Samples Friedman's Two-Way Analysis was used for not normally distributed continuous data. To assess differences between baseline and after the intervention Paired Samples T-test was used for normally distributed continuous data and Related Samples Wilcoxon Signed Rank Test was used for approximately symmetric differences and the Sign Test for not normally distributed data. Bonferroni correction was used for correction for multiple comparisons. To assess correlation between ordinal data and continuous data, Spearman's rho was used. Correlation coefficients $<0.25$ were considered as little to no, $0.25-$ 0.50 as fair, $0.50-0.75$ as moderate to good, and $>0.75$ as good to excellent association [37]. To explore to what extent a change in continuous data could be explained by the baseline values, a univariate linear regression analysis was performed for data with a normal distribution of residuals. Analyses were two-tailed and level of significance was set to $p<0.05$. There was full adherence to the study protocol except for one participant with missing data for the 3 initial assessments (A1-A3) of the quantified $\mathrm{NC}$ as a contributor to spasticity. This participant was excluded from the A1-A3 analysis.

\section{Results}

\section{Inclusion}

A total of 30 persons were tested for eligibility. Nine were excluded as no neural component exceeding the cut off for spasticity according to the NeuroFlexor ${ }^{\text {ra }}$ ( $>3$. 4 Newton) in the wrist flexors could be detected and 1 person due to wrist contractures prohibiting testing. Characteristics of the include participants are presented in Table 1.

\section{Usability and perceived effects}

According to the weekly telephone interviews, the participants used the suit 19.25 times in mean (SD 2.4, range 12-21 times). Two participants did not use the suit during the last week before follow-up due to hospitalization $(n=1)$ and travel $(n=1)$. During stimulation 8 participants were resting (sat or lay down), 10 were resting or moving (e.g. walking, performing ADL or exercising) and 2 only moved during stimulation. Overall usability of the suit was rated as 4.9 in mean (SD 2.4, range 0-9).

Perceived positive effects $(n=9)$ or possible positive effects $(n=3)$ on functioning was experienced by $12(60 \%)$ of the included participants. Among the 12 participants, 6 experienced positive effects in both upper and lower extremity as well as a general effect, 3 only in the upper extremity and 3 only in the lower extremity. Positive effects were most commonly related to a perceived decrease in muscle tone $(n=9)$, improvements in gait pattern functions $(n=7)$ and control of voluntary movement in the upper extremity $(n=6)$. Eight participants did not perceive any positive effects on functioning. Disadvantages was reported by 9 participants and most commonly related to problems with putting on the suit $(n=8)$. One participant reported perceived limitations in mobility during stimulation and 1 participant reported gradual decrease in strength during the intervention period. Adverse events, reported by 3 participants were related to a tickling sensation in the sole of the foot during stimulation $(n=1)$, muscle soreness (like after strenuous exercise, $n=1)$ and an increase in muscle tone during the night $(n=1)$.

\section{Spasticity}

Analysis of the 3 initial assessments (A1-A3) of the quantified $\mathrm{NC}$ as a contributor to spasticity of the wrist 
Table 1 Characteristics of the included participants $(n=20)$

\begin{tabular}{lc}
\hline Age, mean (SD) range & $58.05(12.86) 28-79$ \\
Women/Men, $\mathrm{n}$ & $7 / 13$ \\
Infarction/haemorrhagic, $\mathrm{n}$ & $11 / 9$ \\
Paretic side right/left, $\mathrm{n}$ & $10 / 10$ \\
Time to inclusion, months, mean (SD) range & $67.20(44.30) 19-172$ \\
Independence in walking, Functional Ambulation Categories, (0-5p) ${ }^{\mathrm{a}}$ median (IQR) range & $4.50(1.00) 2-5$ \\
Self-care and mobility, Barthel Index (0-100p) ${ }^{\mathrm{a}}$, median (IQR) range & $95.00(25.00) 40-100$ \\
Cognitive function, Montreal cognitive assessment, (0-30p) $)^{\mathrm{a}}$ mean (SD) range & $21.45(4.22) 12-28$ \\
\hline
\end{tabular}

${ }^{a}$ minimum and maximum points of the score (a lower score indicates increased impairments/limitations)

flexors of the affected hand performed on 19 of the 20 included participants before the start of the intervention, showed no significant difference between assessments (Newton, median (IQR): A1: 13.15 (9.97), A2: 11.63 (11.70), A3: 11.68 (16.45), $p=0.949)$. The test for potential, immediate changes of $\mathrm{NC}$ during one treatment session performed before the intervention showed a decrease in the NC among 10 of the 19 included participants (median (IQR) -2.07 (3.35) Newton), while an increase was found among the remaining 9 participants (median (IQR) 1.42 (7.04) Newton). On a group level no significant difference in the $\mathrm{NC}$ during treatment compared to before treatment was found $(p=0.747)$. However, for the same 19 participants, a significant decrease in the $\mathrm{NC}$ was seen after the 6 weeks intervention period including repeated treatments, based on M1 and M2 data, (Newton, mean (SD): M1: 13.58 (18.15), M2: 10.89 (11.92), $p=0.040)$ and for the total of the 20 participants $(p=0.012)$ (Table 2 and Fig. 3). A total of $60 \%$ of the variance in the difference in $\mathrm{NC}$ of the affected hand could be explained by the baseline $\mathrm{NC}$ value $(\mathrm{R}$ square $=$ $0.600, p=0.000, \mathrm{~B}=-0.418, \mathrm{CI}:-0.587 ;-0.249)$. Three participants had a neural component $>3.4$ Newton in the less affected hand, indicating bilateral spasticity. For the less affected hand no significant difference between M1 and M2 was found (Table 2). Change in the NC for the wrist flexors of the affected hand did not correlate significantly with perceived effect on functioning in the upper extremity (no/possible/perceived effect) $(r=0.240$ $p=0.308)$.

Spasticity according to the MAS was detected at M1 and M2, in both upper and lower extremities in all participants (Table 2). One participant was affected bilaterally in the upper extremity and 7 participants in the lower extremity according to the summarized score of the MAS (MAS-sum score). No significant change between M1 and M2 for the wrist flexors of the affected hand was found according to the MAS $(p=0.319)$ nor for the MAS-sum scores for the upper (affected side $p=$ 0.354 , less affected side $p=0.317$ ) and lower extremities (affected side $p=0.272$, less affected side $p=0.250$ ) (Table 2).

\section{Additional assessments of functioning and disability}

Results of assessed function and activity in the upper and lower extremities are presented in Tables 3 and 4.

Change between M1 and M2 in the FM total scores for the affected upper and lower extremity respectively could not be significantly explained by baseline FM total score (FM-UE: $\mathrm{R}$ square $=0.069, p=0.263, \mathrm{~B}=0.069$, CI: - 0.056; 0.194) (FM-LE: R square $=0.066, p=0.276, \mathrm{~B}=$ -0.113 , CI: -0.323 ; 0.098). However, change between M1 and M2 in the FM-UE total score correlated significantly and fairly with perceived effect in the upper

Table 2 NeuroFlexor ${ }^{\mathrm{TM}}$ components and MAS at M1 and M2

\begin{tabular}{|c|c|c|c|}
\hline Assessment & M1 & M2 & $P$-value \\
\hline NeuroFlexor ${ }^{\mathrm{TM}}$, wrist flexors, affected hand, $\mathrm{NC}^{\mathrm{a}}{ }^{\mathrm{a}}$, Newton, median (IQR)) & $14.09(17.71)$ & $11.30(11.27)$ & 0.023 \\
\hline NeuroFlexorm, wrist flexors, less affected hand $\mathrm{NC}^{\mathrm{a}}$, Newton, median (IQR) & $1.10(2.51)$ & $0.69(1.16)$ & 0.314 \\
\hline MAS, wrist flexors, affected hand $(0-5 p)^{b}$ median (IQR) & $0.00(2.00)$ & $1.00(2.00)$ & 0.319 \\
\hline MAS, wrist flexors, less affected hand $(0-5 p)^{b}$ median (IQR) & $0.00(0.00)$ & $0.00(0.00)$ & N/A" \\
\hline MAS-sum, Upper extremity affected side, summarized score $(0-35 p)^{b}$ median (IQR) & $9.00(7.00)$ & $9.00(8.00)$ & 0.354 \\
\hline MAS-sum, Upper extremity less affected side, summarized score, $(0-35$ p) median (IQR) & $0.00(0.00)$ & $0.00(0.00)$ & 0.317 \\
\hline MAS-sum, Lower extremity affected side, summarized score, (0-30 p $)^{\mathrm{b}}$ median (IQR) & $7.00(9.00)$ & $5.00(3.00)$ & 0.273 \\
\hline MAS-sum, Lower extremity less affected side, summarized score, $(0-30 p)^{b}$ median (IQR) & $0.00(2.00)$ & $0.00(1.00)$ & 0.250 \\
\hline
\end{tabular}

${ }^{a} \mathrm{NC}>3.4$ Newton was considered as hand spasticity (Pennati 2016), ${ }^{\mathrm{b}}$ Summarized minimum and maximum points (no spasticity to rigidity), $" n=1$ participant with detected spasticity 


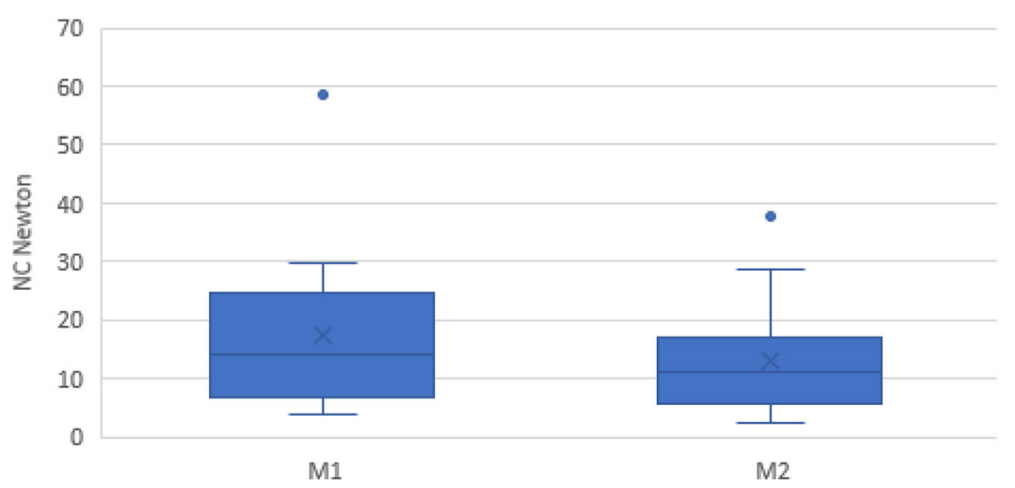

Fig. 3 Neural component (NC) before (M1) and after the 6 weeks intervention (M2)

extremity $(r=0.498, p=0.025)$ and in the corresponding analysis for the change in the total score of the FM-LE and the perceived effect in the lower extremity $(r=$ $0.469, p=0.037)$. No significant correlation was found between the change between M1 and M2 in the ARAT total score of the affected extremity and perceived effect in the upper extremity (correlation coefficient $r 0.123$, $p=0.606)$.

\section{Self-perceived rating of functioning and disability}

Results of self-perceived rating of functioning and disability according to the Stroke Impact Scale is presented in Table 5. No significant change was found between M1 and M2.

\section{Discussion}

This study targets a subgroup of the stroke population living with long-term consequences of hemiparetic stroke including spasticity, impaired sensorimotor function, and activity limitations. The aim of this study was to explore if assessed and perceived functioning and disability was affected by using the Mollii suit for treatment of spasticity in the home setting for 6 weeks. In line with previously reported results from the same study setting [38], approximately $2 / 3$ of the screened eligible participants were found to have a clinically detectable neural component exceeding the cut off for spasticity according to the NeuroFlexor ${ }^{\mathrm{ru}}$. Thus, the participants included in this study may be considered representable for a slightly younger stroke population (mean age 58 years), living with hemiplegia and spasticity longterm after stroke.

Main findings of this study include a significant decrease in $\mathrm{NC}$ of the wrist flexors detected with the NeuroFlexor ${ }^{\mathrm{ma}}$. Manual assessments of upper and lower extremities according to the Ashworth scale however, did not show a significant change. Sensorimotor function in both upper and lower extremities improved significantly according to the FM total scores while assessed activity performance did not, apart from observed grasp, grip, pinch and gross movements assessed with the ARAT. Perceived positive effects on functioning were reported by $60 \%$ and, in line with results from the clinical assessments, effects were most commonly related to a perceived decrease in muscle tone, improvements in gait pattern functions and/or control of voluntary movement in the upper extremity. In addition, perceived positive effects were found to be correlated with improvements in sensorimotor function according to the FM total scores, indicating that perceived effects described by patients may correspond with clinical measures of sensorimotor function. The study is

Table 3 Function and activity at M1 and M2 in the affected upper extremity

\begin{tabular}{|c|c|c|c|}
\hline Assessments & M1 & M2 & $P$ \\
\hline FM-UE, total score $(0-126 p)^{a}$ mean (SD) & $63.90(7.99)$ & $66.55(7.86)$ & 0.000 \\
\hline FM-UE, motor score^ $(0-66 p)^{a}$ mean $(S D)$ & $29.80(14.70)$ & $33.60(16.55)$ & 0.000 \\
\hline FM-UE, sensory function, (0-12p) median (IQR) & $5.50(9.00)$ & $7.50(10.00)$ & 0.032\# \\
\hline FM-UE, passive joint motion, $(0-24)^{a}$ median (IQR) & $20.00(4.00)$ & $21.50(4.00)$ & 0.004 \\
\hline FM-UE, pain, (0-24p) ${ }^{a}$ median (IQR) & $24.00(2.00)$ & $24.00(2.00)$ & 0.719 \\
\hline ARAT total score (0-57p) median (IQR) & $24.50(28.50)$ & $25.00(28.75)$ & 0.000 \\
\hline JAMAR, kilograms mean (SD) & $9.15(4.94)$ & $9.27(5.10)$ & 0.844 \\
\hline
\end{tabular}

${ }^{a}$ minimum and maximum points of the score (a lower score indicates increased impairment) \# not significant after a Bonferroni correction including the FMUE comparisons 
Table 4 Function and activity at $M 1$ and $M 2$ involving the affected lower extremity

\begin{tabular}{|c|c|c|c|}
\hline Assessments & M1 & M2 & $P$ value \\
\hline FM-LE, total score $(0-86 p)^{a}$ mean (SD) & $63.90(7.99)$ & $66.55(7.86)$ & 0.003 \\
\hline FM-LE, motor score $(0-34 p)^{a}$ mean (SD) & $19.60(5.68)$ & $21.70(5.45)$ & 0.001 \\
\hline FM-LE, sensory $(0-12 p)^{a}$ mean $(S D)$ & $7.25(3.74)$ & $7.30(3.72)$ & 0.874 \\
\hline FM-LE, passive joint motion, (0-20p) ${ }^{a}$ median (IQR) & $18.00(3.00)$ & $19.00(3.00)$ & 0.013\# \\
\hline FM-LE, pain, (0-20p) $)^{a}$ mean (SD) & $20.00(1.00)$ & $20.00(1.00)$ & 0.527 \\
\hline Berg balance scale (0-56p) ${ }^{a}$ median (IQR) & $46.00(13.00)$ & $49.50(9.00)$ & 0.063 \\
\hline $10 \mathrm{~m}$ walk test, seconds, mean (SD) & $22.22(28.77)$ & $21.76(25.93)$ & 0.629 \\
\hline 6 min walk, meters, mean (SD) & $252.88(153.44)$ & $255.50(155.60)$ & 0.746 \\
\hline
\end{tabular}

${ }^{a}$ minimum and maximum points of the score (a lower score indicates increased impairment)

\# not significant after a Bonferroni correction including the FM- LE comparisons

explorative and may guide future controlled studies needed to confirm these results.

Compliance and perceived effects were thoroughly monitored by structured weekly telephone interviews. Overall, compliance to study instructions was high. The suit was used in mean 19.25 out of potentially 21 times indicating that use of the Mollii ${ }^{\bullet}$ suit in this patient population is feasible, which agrees with a previous study [18]. Nevertheless, mean ratings of overall usability were modest and the main reported perceived disadvantage was related to problems with putting on the suit. These results indicate that further development of the suit may include a more flexible fabric and design to ease the donning without compromising the tight fit needed to adhere the electrodes to the skin surface.

In this study we used the standardized evaluated NeuroFlexor ${ }^{\mathrm{Tu}}$ method to quantify and differentiate the neural, i.e. spasticity, elastic and viscosity components of an increased resistance to passive stretch [21, 25-27, 38]. The observation of stable baseline the NC values before the start of the intervention (A1-A3) lends strong

Table 5 Self-perceived ratings of functioning and disability according to the Stroke Impact scale at M1 and M2 and test of significant differences between M1 and M2

\begin{tabular}{llll}
\hline Domains $^{\text {a }}$ & $M 1$ & M2 & $P$ value \\
\hline 1.Strength, mean (SD) & $33.75(13.96)$ & $39.68(10.97)$ & 0.073 \\
2.Memory and thinking, mean (SD) & $78.93(14.74)$ & $80.18(13.73)$ & 0.612 \\
3.Emotion, mean (SD) & $72.08(16.75)$ & $71.94(17.50)$ & 0.947 \\
4.Communication, median (IQR) & $87.50(16.07)$ & $85.71(9.82)$ & 0.219 \\
5.ADL, mean (SD) & $65.90(21.97)$ & $66.67(21.51)$ & 0.618 \\
6.Mobility, mean (SD) & $74.86(18.21)$ & $76.39(18.28)$ & 0.346 \\
7.Hand function, median (IQR) & $0.00(35.00)$ & $10.00(38.75)$ & 0.301 \\
8.Social Participation, mean (SD) & $54.53(29.48)$ & $55.78(23.54)$ & 0.775 \\
9.Recovery ${ }^{b}$, mean (SD) & $50.05(24.72)$ & $53.30(23.99)$ & 0.390 \\
\hline
\end{tabular}

${ }^{a}$ Each domain ranges from 0 to $100(0=$ maximum limitation and restriction to $100=$ no limitation or restriction). ${ }^{\mathrm{b}}$ Rated on a vertical scale, ranging from $0=$ no recovery to $100=$ full recovery support to the observed significant changes in the NC between the start (M1) and the end of the intervention (M2). While repeated baseline measurements (A1-A3) showed no significant variation, spasticity was significantly lower after the 6 weeks intervention and $60 \%$ of the variance in the difference in the neural component of the affected hand could be explained by the baseline $\mathrm{NC}$ value, indicating that the effect on the $\mathrm{NC}$ will be larger if the $\mathrm{NC}$ is high at baseline.

Notably, only the wrist flexors were assessed with the NeuroFlexor $^{\mathrm{Tm}}$ hand module. This is a limitation in a study assessing effects in both upper and lower extremities. Therefore, assessments with the MAS was performed. These results exhibited no significant change after the intervention although the most commonly reported positive effect was a decrease in muscle tone. These results may reflect that the MAS has low accuracy for diagnosing reflex-mediated resistance to passive stretch $[39,40]$. A recent study assessing the validity of the NeuroFlexor ${ }^{\mathrm{ma}}$ and the MAS confirms that clinical assessment according to the modified Ashworth scale cannot differentiate the active $\mathrm{NC}$ from the passive elastic component [41]. A new NeuroFlexor ${ }^{\text {ru }}$ foot module has been developed and is currently tested on a stroke population and in healthy subjects.

In the current study, 3 participants had a detected neural component above cut-off ( $>3.4$ Newton) in the less affected hand, and 7 participants had increased resistance to passive stretch in the lower extremity according to the Ashworth scale, indicating bilateral affection. These findings are in agreement with previous studies demonstrating that motor function on the ipsilesional side may also be affected due to an interhemispheric imbalance after stroke [38, 42]. Taking the questioned validity of the MAS into consideration [41], the bilateral findings based on assessment with the modified Ashworth scale could also be a result of a higher resistance in the elastic component rather than a neural. 
Given the observed results on sensorimotor function and upper extremity performance, future studies should move on to evaluate the effect of combining treatment with the Mollii suit with rehabilitation interventions targeting activity performance. In clinical practice, treatment of spasticity (both pharmacological and nonpharmacological) is strongly recommended to be combined with a multidisciplinary approach with goals set at an activity and participation level [43, 44]. As presented in this study, a decrease in NC was detected in $50 \%$ of the participants while resting in a sitting position during a single treatment with the Mollii ${ }^{\circ}$ suit. However, there was no significant decrease of $\mathrm{NC}$ on a group level in this test situation while a significant decrease in the $\mathrm{NC}$ was seen after recurrent treatments over 6 weeks when $60 \%$ performed everyday life activities in association with treatments with Mollii. This reasoning is supported by positive results from a systematic review on treatments of spasticity using TENS during activity [14]. Thus, both repetition of treatments and that treatment is performed during activity may be contributing factors and explain why $\mathrm{NC}$ did not decrease significantly on a group level during one treatment session performed at rest.

Future studies should also consider a double blinded design where the suit is used turned on or off to explore this further. The electric stimulation given by the suit and its effect on spasticity was the focus of this study, still the full body compression that the suit provides is a factor that may be considered. This could potentially increase the tactile and proprioceptive input, factors that are known to be important for motor recovery after stroke [45].

\section{Conclusion}

This is the first study that demonstrates the feasibility of regular use of the Mollii method in the home setting and potentially beneficial effects after a 6 weeks intervention on spasticity and sensorimotor function in patients with chronic stroke. Results need to be confirmed in a larger controlled study preferably combined with goal directed training interventions to enhance possible effects on activity and participation domains.

\footnotetext{
Abbreviations

M1: Assessment before the intervention; M2: Assessment after the 6 weeks intervention; ARAT: Action Research Arm test; EC: Elastic component; FM: Fugl-Meyer Assessment of motor recovery; FM-UE: Fugl-Meyer Assessment for the upper extremities; FM-LE: Fugl-Meyer Assessment for the lower extremities; IQR: Interquartile Range; MAS: Modified Ashworth scale; MAS-sum: Modified Ashworth scale summarized score; NC: Neural component; SD: Standard deviation; TENS: Transcutaneous electrical nerve stimulation
}

\section{Authors' contributions}

SP and JB have made substantial contributions to the conception of the work and SP, JB and GP to the design of the work. GP and HB to the data collection and SP and JB to the analysis and interpretation of data. SP, JB, wrote the manuscript together with GP and $\mathrm{HB}$ and all have approved the submitted version. All authors have agreed both to be personally accountable for the author's own contributions and to ensure that questions related to the accuracy or integrity of any part of the work, even ones in which the author was not personally involved, are appropriately investigated, resolved, and the resolution documented in the literature.

\section{Funding}

This study was funded by grants from Eurostars, EUREKA and the European Commission (https://www.eurostars-eureka.eu/), reference: 10627/15/24722/ Ae and the Molliiø suits were provided by Inerventions AB (info@mollii.com). The study sponsors were not involved in the study design, collection of data, analysis, interpretation of data, writing the manuscript or the decision to submit the manuscript for publication. Open access funding provided by Karolinska Institute.

\section{Availability of data and materials}

The datasets generated and/or analyzed during the current study will be shared upon reasonable request. All data are included in this published article.

\section{Ethics approval and consent to participate}

The study was approved by the Swedish Ethical Review Authority (2017/ 935-31). Only participants who were able to understand written and oral study information and could express informed consent were included. They were informed that they could discontinue participation at any time.

\section{Consent for publication}

Consent for publication was given by the person wearing the Mollii suit in Fig. 1.

\section{Competing interests}

The authors declare that they have no competing interests.

Received: 10 May 2020 Accepted: 29 July 2020

Published online: 10 August 2020

\section{References}

1. Lance JW. Spasticity: disordered motor control. In: Feldman RG, Young RR, Koella WP, editors. Symposium Synposis. 4th ed; 1980. p. 485-94.

2. Gracies JM. Pathophysiology of spastic paresis. Il: emergence of muscle overactivity. Muscle Nerve. 2005;31(5):552-71.

3. Sommerfeld DK, Eek EU, Svensson AK, Holmqvist LW, von Arbin MH. Spasticity after stroke: its occurrence and association with motor impairments and activity limitations. Stroke. 2004;35(1):134-9.

4. Lundstrom E, Terent A, Borg J. Prevalence of disabling spasticity 1 year after first-ever stroke. Eur J Neurol. 2008;15(6):533-9.

5. Urban PP, Wolf T, Uebele M, Marx JJ, Vogt $T$, Stoeter $P$, et al. Occurence and clinical predictors of spasticity after ischemic stroke. Stroke. 2010;41(9):2016-20.

6. Bakheit AM, Fedorova NV, Skoromets AA, Timerbaeva SL, Bhakta BB, Coxon $L$. The beneficial antispasticity effect of botulinum toxin type $a$ is maintained after repeated treatment cycles. J Neurol Neurosurg Psychiatry. 2004;75(11):1558-61

7. Brashear A, Gordon MF, Elovic E, Kassicieh VD, Marciniak C, Do M, et al. Intramuscular injection of botulinum toxin for the treatment of wrist and finger spasticity after a stroke. N Engl J Med. 2002;347(6):395-400.

8. McCrory P, Turner-Stokes L, Baguley IJ, De Graaff S, Katrak P, Sandanam J, et al. Botulinum toxin a for treatment of upper limb spasticity following stroke: a multi-Centre randomized placebo-controlled study of the effects on quality of life and other person-centred outcomes. J Rehabil Med. 2009; 41(7):536-44.

9. Andringa A, van de Port I, van Wegen E, Ket J, Meskers C, Kwakkel G. Effectiveness of botulinum toxin treatment for upper limb spasticity Poststroke over different ICF domains: a systematic review and metaanalysis. Arch Phys Med Rehabil. 2019;100(9):1703-25.

10. Ward AB, Wissel J, Borg J, Ertzgaard P, Herrmann C, Kulkarni J, et al. Functional goal achievement in post-stroke spasticity patients: the BOTOX (R) economic spasticity trial (BEST). J Rehabil Med. 2014;46(6):504-13. 
11. Wissel J, Ganapathy V, Ward AB, Borg J, Ertzgaard P, Herrmann C, et al. OnabotulinumtoxinA improves pain in patients with post-stroke spasticity: findings from a randomized, double-blind, placebo-controlled trial. J Pain Symptom Manag. 2016;52(1):17-26.

12. Gupta AD, Chu WH, Howell S, Chakraborty S, Koblar S, Visvanathan R, et al. A systematic review: efficacy of botulinum toxin in walking and quality of life in post-stroke lower limb spasticity. Syst Rev. 2018;7(1):1.

13. Mahmood A, Veluswamy SK, Hombali A, Mullick A, Manikandan N, Solomon $J M$. Effect of transcutaneous electrical nerve stimulation on spasticity in adults with stroke: a systematic review and meta-analysis. Arch Phys Med Rehabil. 2019;100(4):751-68.

14. Mills PB, Dossa F. Transcutaneous electrical nerve stimulation for Management of Limb Spasticity a systematic review. Am J Phys Med Rehab. 2016;95(4):309-18.

15. Marcolino MAZ, Hauck M, Stein C, Schardong J, Pagnussat AS, Plentz RDM. Effects of transcutaneous electrical nerve stimulation alone or as additional therapy on chronic post-stroke spasticity: systematic review and meta-analysis of randomized controlled trials. Disabil Rehabil. 2018; 1:1-13.

16. Perez MA, Field-Fote EC, Floeter MK. Patterned sensory stimulation induces plasticity in reciprocal ia inhibition in humans. J Neurosci. 2003:23(6):2014-8.

17. Tinazzi M, Zarattini S, Valeriani M, Romito S, Farina S, Moretto G, et al. Longlasting modulation of human motor cortex following prolonged transcutaneous electrical nerve stimulation (TENS) of forearm muscles: evidence of reciprocal inhibition and facilitation. Exp Brain Res. 2005;161(4): 457-64.

18. Ertzgaard P, Alwin J, Sorbo A, Lindgren M, Sandsjo L. Evaluation of a selfadministered transcutaneous electrical stimulation concept for the treatment of spasticity: a randomized placebo-controlled trial. Eur J Phys Rehabil Med. 2018;54(4):507-17.

19. Holden MK, Gill KM, Magliozzi MR, Nathan J, Piehl-Baker L. Clinical gait assessment in the neurologically impaired. Reliability and meaningfulness. Phys Ther. 1984;64(1):35-40.

20. Nordin A, Murphy MA, Danielsson A. Intra-rater and inter-rater reliability at the item level of the action research arm test for patients with stroke. J Rehabil Med. 2014;46(8):738-45.

21. Pennati GV, Plantin J, Borg J, Lindberg PG. Normative NeuroFlexor data for detection of spasticity after stroke: a cross-sectional study. J Neuroeng Rehab. 2016;13:30

22. Mahoney FI, Barthel DW. Functional evaluation: the Barthel index. Maryland State Med J. 1965;14:61-5.

23. Nasreddine ZS, Phillips NA, Bedirian V, Charbonneau S, Whitehead V, Collin I, et al. The Montreal cognitive assessment, MoCA: a brief screening tool for mild cognitive impairment. J Am Geriatr Soc. 2005;53(4):695-9.

24. World Health Organization. International classification of functioning, disability and health; 2018. http://apps.who.int/classifications/icfbrowser/ . Accessed 4 Aug 2020.

25. Lindberg PG, Gaverth J, Islam M, Fagergren A, Borg J, Forssberg H. Validation of a new biomechanical model to measure muscle tone in spastic muscles. Neurorehabil Neural Repair. 2011;25(7):617-25.

26. Gaverth J, Sandgren M, Lindberg PG, Forssberg H, Eliasson AC. Test-retest and inter-rater reliability of a method to measure wrist and finger spasticity. J Rehabil Med. 2013;45(7):630-6.

27. Gaverth J, Eliasson AC, Kullander K, Borg J, Lindberg PG, Forssberg $H$. Sensitivity of the NeuroFlexor method to measure change in spasticity after treatment with botulinum toxin a in wrist and finger muscles. J Rehabil Med. 2014;46(7):629-34.

28. Bohannon RW, Smith MB. Interrater reliability of a modified Ashworth scale of muscle spasticity. Phys Ther. 1987;67(2):206-7.

29. Fleuren JF, Voerman GE, Erren-Wolters CV, Snoek GJ, Rietman JS, Hermens $\mathrm{HJ}$, et al. Stop using the Ashworth scale for the assessment of spasticity. J Neurol Neurosurg Psychiatry. 2010;81(1):46-52.

30. Fugl-Meyer AR, Jaasko L, Leyman I, Olsson S, Steglind S. The post-stroke hemiplegic patient. 1. A method for evaluation of physical performance. Scand J Rehabil Med. 1975;7(1):13-31.

31. Wade DT, Wood VA, Heller A, Maggs J, Langton HR. Walking after stroke. Measurement and recovery over the first 3 months. Scand J Rehabil Med. 1987;19(1):25-30.

32. Kosak M, Smith T. Comparison of the 2-, 6-, and 12-minute walk tests in patients with stroke. J Rehabil Res Dev. 2005;42(1):103-7.
33. Berg KO, Wood-Dauphinee SL, Williams JI, Maki B. Measuring balance in the elderly: validation of an instrument. Can J Public Health. 1992;83(Suppl 2): S7-11.

34. Berg K, Wood-Dauphinee S, Williams Jl. The balance scale: reliability assessment with elderly residents and patients with an acute stroke. Scand Rehabil Med. 1995;27(1):27-36.

35. Duncan PW, Wallace D, Lai SM, Johnson D, Embretson S, Laster LJ. The stroke impact scale version 2.0. Evaluation of reliability, validity, and sensitivity to change. Stroke. 1999;30(10):2131-40.

36. Duncan PW, Bode RK, Min Lai S, Perera S. Glycine antagonist in neuroprotection Americans I. Rasch analysis of a new stroke-specific outcome scale: the stroke impact scale. Arch Phys Med Rehabil. 2003;84(7): 950-63.

37. Portney LGWM. Foundation of Clinical Research: application to practice. Upper Sadler River: Prentice Hall 912; 2000.

38. Plantin J, Pennati GV, Roca P, Baron JC, Laurencikas E, Weber K, et al. Quantitative assessment of hand spasticity after stroke: imaging correlates and impact on motor recovery. Front Neurol. 2019;10:836.

39. Lorentzen J, Grey MJ, Crone C, Mazevet D, Biering-Sorensen F, Nielsen JB. Distinguishing active from passive components of ankle plantar flexor stiffness in stroke, spinal cord injury and multiple sclerosis. Clin Neurophysiol. 2010;121(11):1939-51.

40. Alibiglou L, Rymer WZ, Harvey RL, Mirbagheri MM. The relation between Ashworth scores and neuromechanical measurements of spasticity following stroke. J Neuroeng Rehab. 2008;5:18.

41. Andringa A, van Wegen E, van de Port I, Kwakkel G, Meskers C. Measurement properties of the NeuroFlexor device for quantifying neural and non-neural components of wrist hyper-resistance in chronic stroke. Front Neurol. 2019;10:730.

42. Dodd KC, Nair VA, Prabhakaran V. Role of the Contralesional vs. Ipsilesional hemisphere in stroke recovery. Front Hum Neurosci. 2017;11:1.

43. Sunnerhagen KS, Olver J, Francisco GE. Assessing and treating functional impairment in poststroke spasticity. Neurology. 2013;80(3 Suppl 2):S35-44.

44. Naro A, Leo A, Russo M, Casella C, Buda A, Crespantini A, et al. Breakthroughs in the spasticity management: are non-pharmacological treatments the future? J Clin Neurosci. 2017;39:16-27.

45. Bolognini N, Russo C, Edwards DJ. The sensory side of post-stroke motor rehabilitation. Restor Neurol Neurosci. 2016;34(4):571-86.

\section{Publisher's Note}

Springer Nature remains neutral with regard to jurisdictional claims in published maps and institutional affiliations.
Ready to submit your research? Choose BMC and benefit from:

- fast, convenient online submission

- thorough peer review by experienced researchers in your field

- rapid publication on acceptance

- support for research data, including large and complex data types

- gold Open Access which fosters wider collaboration and increased citations

- maximum visibility for your research: over $100 \mathrm{M}$ website views per year

At BMC, research is always in progress.

Learn more biomedcentral.com/submissions 